\title{
Neurovascular and neuroinflammatory mechanisms associated with mood disorders
}

\author{
Gianfranco Spalletta ${ }^{1,2}$, Gabriele Sani ${ }^{3,4}$ \\ ${ }^{1}$ Neuropsychiatry Laboratory, Department of Clinical and Behavioral Neurology, Scientific Institute for Research, Hospitalisation \\ and Health Care, Santa Lucia Foundation, 00179 Rome, Italy. \\ ${ }^{2}$ Department of Psychiatry and Behavioral Sciences, Baylor College of Medicine, Houston, TX 77030, USA. \\ ${ }^{3}$ Department of Neurosciences, Mental Health and Sensory Organs, Sapienza University of Rome, School of Medicine and \\ Psychology, Sant'Andrea Hospital, 00192 Rome, Italy. \\ ${ }^{4}$ Centro Lucio Bini, 00193 Rome, Italy.
}

According to the World Health Organization, mood disorders are a major source of morbidity, disability and mortality worldwide. ${ }^{[1]}$ In fact, they are the leading cause of suicide. ${ }^{[2]}$ Consistent data have been collected regarding their epidemiology and clinical, neurobiological and neuropsychological characteristics but their etiology and pathophysiology still remain to be elucidated. The dearth of data limits the possibility of developing new therapeutic strategies aimed at improving patient outcomes.

Recently, an increasing number of studies have focused on neuroinflammation as a potential mechanism involved in the etiopathogenesis of mood disorders. ${ }^{[3]}$ Before this, a possible relationship between inflammation and psychiatric disorders had been hypothesized. Julius Wagner-Jauregg, the first psychiatrist to be awarded the Nobel Prize in 1927, started from the observations of Hippocrates and Galen and noted that patients diagnosed with psychiatric disorders improved after fever attacks. Thus, he proposed treating them by artificially inducing fever (pyretotherapy) ${ }^{[4]}$ This treatment strategy implies a primary role of inflammation in the pathophysiology of psychiatric disorders. More recently, this view received new impetus from studies that focused on several inflammatory biomarkers [e.g. interleukin-1 (IL-1), IL-6,

Corresponding Author: Dr. Gianfranco Spalletta, Neuropsychiatry Laboratory, Department of Clinical and Behavioral Neurology, Scientific Institute for Research, Hospitalisation and Health Care Santa Lucia Foundation, Via Ardeatina 306, 00179 Rome, Italy.

E-mail: g.spalletta@hsantalucia.it

\begin{tabular}{|l|l|}
\hline \multicolumn{2}{|c|}{ Access this article online } \\
\hline Quick Response Code: & \\
\hline & Website: \\
\hline & www.nnjournal.net \\
& \\
\hline
\end{tabular}

IL-18, tumor necrosis factor- $\alpha$ (TNF- $\alpha$ ), interferon- $\alpha$ and brain-derived neurotrophic factor]. ${ }^{[5-8]}$

The advent of the psychopharmacological era, in general, and of antidepressants, in particular, led clinicians and researchers to concentrate their efforts on the monoaminergic hypothesis of mood disorders. This research line became the standard against which every case had to be measured. In fact, bioamine research in mood disorders attracted the vast majority of resources. Although this research line helped the scientific community gain some insights into the pathophysiology of mood disorders, it did not succeed in dissecting the mystery of mood disorder mechanisms. Some anti-inflammatory properties of anti-depressants ${ }^{[9]}$ and mood stabilizers ${ }^{[10]}$ such as serotonin selective reuptake inhibitors, lithium and valproate have been found, but studies are still few and results are inconsistent. Thus, there is a need to explore new pathways to improve our understanding and develop new treatments.

Inflammation is a fundamental physiological homeostatic response of the entire body, which is connected to the stress response, making it part of Selye's "general adaptation syndrome". ${ }^{[11]}$ It may produce beneficial effects if it is working well and is well-tuned, or it may produce damage and unintended consequences if there is something wrong with its mechanisms, causing it to function inadequately. Undesired consequences may include alterations of mood, sleep, food intake, energy, volition and cognition,

This is an open access article distributed under the terms of the Creative Commons Attribution-NonCommercial-ShareAlike 3.0 License, which allows others to remix, tweak, and build upon the work non-commercially, as long as the author is credited and the new creations are licensed under the identical terms.

For reprints contact: nn_editor001@nnjournal.net

Cite this article as: Spalletta G, Sani G. Neurovascular and neuroinflammatory mechanisms associated with mood disorders. Neuroimmunol Neuroinflammation 2015;2:193-4.

Received: 11-04-2015; Accepted: 20-04-2015 
all of which are part of the classical symptomatology of mood disorders, as well as fever. Cerebrovascular accidents are often associated with the onset of mood disorders, mainly depression. As recently noted by Spalletta et al. ${ }^{[8]}$ the inflammatory process plays a central role in the onset of poststroke depression because several proinflammatory cytokines, produced during stroke, such as IL-1, IL-6, TNF- $\alpha$ or IL-18 may lead to its amplification, particularly in limbic areas. This may cause widespread activation of indoleamine 2,3-dioxygenase and subsequently serotonin depletion in paralimbic regions, such as the ventral lateral frontal cortex, the polar temporal cortex and the basal ganglia.

In this special issue of Neuroimmunology and Neuroinflammation, entitled "neurovascular and neuroinflammatory mechanisms associated with mood disorders", the authors focus on different perspectives. Kotzalidis et al. ${ }^{[12]}$ and Panaccione et al. ${ }^{[13]}$ review the important role of neuroinflammatory mechanisms in bipolar disorders and manic symptoms. They highlight how critical the imbalance between pro-inflammatory and anti-inflammatory cytokines and more generally, the perturbation of the inflammatory system, are in order to identify their causes and phases. Quaranta et al. ${ }^{[14]}$ hypothesize a possible role of autoimmunity, which may be more relevant in psychotic than in nonpsychotic mood disorders. They review the literature on the relationship between dysregulation of immune homeostasis and psychiatric disorders and suggest that cellular damage due to immune-mediated mechanisms involving excitotoxicity, oxidative stress and mitochondrial dysfunction may be present in medical disorders and severe mood and psychotic disorders, thus potentially reflecting common underlying vulnerabilities. The role of inflammation in other specific clinical populations is also investigated. Serra et al. ${ }^{[15]}$ show preliminary data which suggest there is a relationship between the inflammatory process and juvenile bipolar disorder. Marangoni et al. ${ }^{[16]}$ point out the high prevalence of bipolar disorder in patients with multiple sclerosis; they highlight the need for long-term observational studies to determine whether common mechanisms underlie the two disorders. Serafini et al. ${ }^{[17]}$ propose to use the detection of white matter abnormalities as biological markers of poor outcome, often characterized by suicidal behavior, in patients with major depressive disorders. Lastly, Liguori et al. ${ }^{[18]}$ extensively review the role of gamma-aminobutyric acid in mood disorders and the involvement of different inflammatory mechanisms in the development of excitatory symptoms.

What remains unanswered is the following question: are psychiatric disorders in general, and mood disorders in particular, merely an expression of different abnormalities of inflammation at the system level and in the brain, which are also called neuroinflammation? This provocatory question perfectly summarizes the key outstanding issue. Taken together, these reviews represent current research in the field of mood disorders.
By improving our understanding of the mechanisms underlying such disorders, there is hope that in the near future the development of novel therapeutic approaches will result in better outcome.

Financial support and sponsorship

Nil.

Conflicts of interest

There are no conflicts of interest.

\section{REFERENCES}

1. Whiteford HA, Degenhardt L, Rehm J, Baxter AJ, Ferrari AJ, Erskine HE, Charlson FJ, Norman RE, Flaxman AD, Johns N, Burstein R, Murray CJ, Vos T. Global burden of disease attributable to mental and substance use disorders: findings from the Global Burden of Disease Study 2010. Lancet 2013;382:1575-86.

2. Sani G, Tondo L, Koukopoulos A, Reginaldi D, Kotzalidis GD, Koukopoulos AE, Manfredi G, Mazzarini L, Pacchiarotti I, Simonetti A, Ambrosi E, Angeletti G, Girardi P, Tatarelli R. Suicide in a large population of former psychiatric inpatients. Psychiatry Clin Neurosci 2011;65:286-95.

3. Stertz L, Magalhães PV, Kapczinski F. Is bipolar disorder an inflammatory condition? The relevance of microglial activation. Curr Opin Psychiatry 2013;26:19-26.

4. Wagner-Jauregg J. About the effect of fever on psychosis. Jahbuch Psychiatr Neurol 1887;7:94-131.

5. Girgis RR, Kumar SS, Brown AS. The cytokine model of schizophrenia: emerging therapeutic strategies. Biol Psychiatry 2014;75:292-9.

6. Lichtblau N, Schmidt FM, Schumann R, Kirkby KC, Himmerich H. Cytokines as biomarkers in depressive disorder: current standing and prospects. Int Rev Psychiatry 2013;25:592-603.

7. Spalletta G, Bossù $\mathrm{P}$, Ciaramella $\mathrm{A}$, Bria $\mathrm{P}$, Caltagirone $\mathrm{C}$, Robinson RG. The etiology of poststroke depression: a review of the literature and a new hypothesis involving inflammatory cytokines. Mol Psychiatry 2006;11:984-91.

8. Spalletta G, Cravello L, Imperiale F, Salani F, Bossù P, Picchetto L, Cao M, Rasura M, Pazzelli F, Orzi F, Caltagirone C, Robinson RG, Cacciari C. Neuropsychiatric symptoms and interleukin-6 serum levels in acute stroke. J Neuropsychiatry Clin Neurosci 2013;25:255-63.

9. Walker FR. A critical review of the mechanism of action for the selective serotonin reuptake inhibitors: do these drugs possess anti-inflammatory properties and how relevant is this in the treatment of depression? Neuropharmacology 2013;67:304-17.

10. Chiu CT, Wang Z, Hunsberger JG, Chuang DM. Therapeutic potential of mood stabilizers lithium and valproic acid: beyond bipolar disorder. Pharmacol Rev 2013;65:105-42.

11. Selye H. A syndrome produced by diverse nocuous agents. Nature 1936;138:32.

12. Kotzalidis GD, Ambrosi E, Simonetti A, Cuomo I, Del Casale A, Janiri D, Savoja V, Rapinesi C. Neuroinflammation in bipolar disorders. Neuroimmunol Neuroinflamm 2015;2:252-62.

13. Panaccione I, Spalletta G, Sani G. Neuroinflammation and excitatory symptoms. Neuroimmunol Neuroinflamm 2015;2:215-27.

14. Quaranta G, Bucci N, Toni C, Perugi G. Psychotic and non-psychotic mood disorders in autoimmune encephalitis: diagnostic issues and research implications. Neuroimmunol Neuroinflamm 2015;2:228-36.

15. Serra G, De Chiara L, Marangoni C, Faedda GL. The role of neuroinflammation in juvenile bipolar disorder. Neuroimmunol Neuroinflamm 2015;2:244-51.

16. Marangoni C, Nanni MG, Grassi L, Faedda GL. Bipolar disorder preceding the onset of multiple sclerosis: a review. Neuroimmunol Neuroinflamm 2015;2:195-99.

17. Serafini G, Amore M, Rihmer Z. Microstructural brain abnormalities, affective temperaments, and suicidal behavior in patients with major depression. Neuroimmunol Neuroinflamm 2015;2:200-14.

18. Liguori M, Manchia M, Tondo L. The role of anti-glutamic acid decarboxylase autoantibodies in mood disorders: a review. Neuroimmunol Neuroinflamm 2015;2:237-43. 